\title{
HOW TO DEVELOP RURAL INFORMATIZATION IN CHINA
}

\author{
Junjing Yuan ${ }^{1}$, Daoliang $\mathrm{Li}^{2}$, Hongwen $\mathrm{Li}^{1, *}$ \\ ${ }^{1}$ College of Engineering, China Agricultural University, Beijing, China, 100083 \\ ${ }^{2}$ College of Information and Electrical Engineering, China Agricultural University, Beijing, \\ China, 100083 \\ * Corresponding author, Address: P.O. Box 46, College of Engineering, China Agricultural \\ University, 17 Tsinghua East Road, Beijing, 100083, P. R. China, Tel: +86-10-62737631, \\ Fax: +86-10-62737300, Email: lhwen@cau.edu.cn
}

\begin{abstract}
This paper analyses the status of rural informatization of China from different perspectives, including China's development timeline, info-platform, resources, geography, and income; and puts forward some recommendations of development as follows: (1) Strengthening government promotion and infrastructure construction. (2) Increasing optimism and confidence of farmers. (3) Providing training and facilitating discussion. (4) Solving localization issues. (5) Providing satisfactory goods and services.
\end{abstract}

Keywords: rural informatization, digital divide, information and communication technologies, ICT, recommendation

\section{INTRODUCTION}

Global history has shown that science and technology are the main drivers of social and economic development. In the past two decades, information and communication technologies (hereafter abbreviated as ICT) have made rapid progress, which has resulted in science and technology quickly becoming widespread (Wang, 2006). Currently, traditional agriculture is undergoing a process of modernization, the development and dissemination of rural information and the application of ICT in the agricultural field can not only improve rural conditions, but also raise the level of agriculture currently being practiced.

Yuan, J., Li, D. and Li, H., 2008, in IFIP International Federation for Information Processing, Volume 258; Computer and Computing Technologies in Agriculture, Vol. 1; Daoliang Li; (Boston: Springer), pp. 449-456. 
From the beginning of the 21st century, ICT have become more common and expanded around the globe. On one hand, computers are more readily available to the ordinary person and the costs (table 1) of computers are declining rapidly (Singh, 2003). On the other hand, the imbalance of the information network development has enlarged the digital divide, which not only exits between developed countries and developing countries, but also between urban and rural areas in developing countries (Li, 2006). Currently, many poor families or/and minority families are living on the less fortunate side of the divide.

Table 1. Falling Costs of Computing (dollars)

\begin{tabular}{lrc}
\hline Costs of computing & 1970 & 1999 \\
\hline 1 Mhz of processing power & 7601 & 0.17 \\
1 megabit of storage & 5257 & 0.17 \\
1 trillion bits sent & 150000 & 0.12 \\
\hline
\end{tabular}

\section{THE STATUS OF RURAL INFORMATIZATION IN CHINA}

China is now one of the most important developing countries in the world. The nation's rural informatization has been developing for over 20 years, but there are characteristics of China's rural informatization that must be taken into account, such as late entry, rapid development, unbalanced disemination and so on.

From a time perspective, rural informatization of China is currently 10 to 20 years behind that of developed countries, but its progress has been made at a particularly rapid rate. In the 1980s, computer technology was applied in the field of agriculture, and subsequent to the 1990s, agricultural informatization systems were established and rural informatization developed quickly. For instance, the "Golden Agriculture Project," agricultural websites and national agricultural informatization systems were promoted and established by the Ministry of Agriculture and other agricultural institutes at this time. After the turn of the 21 st century, developing rural informatization was listed in the Outline of the Tenth FiveYear Plan for National Economic \& Social Development of the People's Republic of China and additionally in the Eleventh Five-Year Plan.

From an info-platform perspective, the government has invested a large amount of funds to construct the info-platform, and has established the telecommunication network with relatively advanced technology. Today, the number of both fixed line telephones and mobile phones in China is the largest in the world, and the number of people with access to the internet has 
reached 123 million on the Chinese mainland (Tong, 2006). According to the Chinese Ministry of Information \& Industry, by implementing the "Village Coverage Project," the volume of telephones in rural areas increased rapidly. By the end of 2005, there were 11 provinces and cities where every basic village could be reached by telephone, and $97.1 \%$ of all villages in the entire country could be reached by telephone. By the end of 2006, the proportion increased to $98.9 \%$, with 24 provinces and cities where every basic village could be reached by telephone (Yao, 2007). According to the China Statistical Report (NBSC, 2001-2007), the telephone volume per 100 Chinese people and the number of rural fixed line telephone subscribers has increased quickly from the year 2000 (see fig. 1 and fig. 2). Additionally, statistical information from the State Administration of Radio Film and Television shows that, after the extension of the "Village Coverage Project," the proportion of towns and villages covered by radio and television broadcasts is respectively $99.16 \%$ and $96.43 \%$.

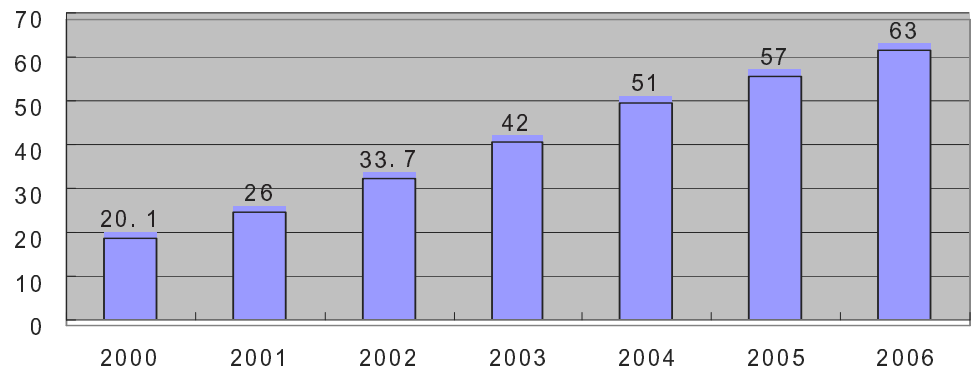

Fig. 1. Telephone volume per 100 Chinese people

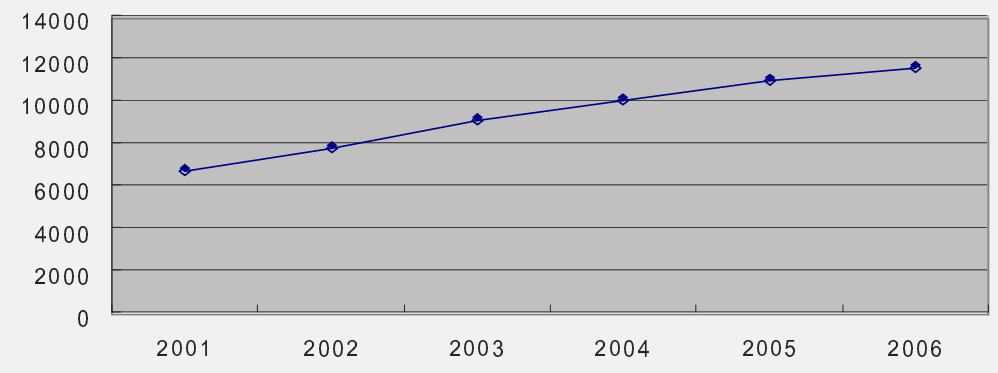

Fig. 2. Number $\left(\times 10^{4}\right)$ of rural fixed line telephone subscribers

From a resource perspective, rural or agricultural informatization resources are consistently deficient and many resources are out of date. The 17th statistical report of CNNIC shows that there were 694,200 websites in China by Dec. 31,2005 with only $0.66 \%$ of the total related to agriculture and rural communities. 
From a geographic perspective (NBSC, 2000-2007), the majority of agricultural websites and information service stations are mostly based in Beijing and some coastal regions, with only a few located in China's western provinces. The total proportion of agricultural websites in five areas (including Beijing, Shandong, Zhejiang, Jiangsu, and Guangdong) exceeds more than 50\% of the total number in the whole country, while in Yunnan, Gansu and other western provinces, the quantity of agricultural websites and libraries is considerably less (Wang, 2006; Wan et al., 2006).

From an income perspective, the proportion of rural population to total population is very high, and the degree of modernization is low. In fig. 4, the decreasing trend of the Engel coefficient for rural households is obvious, while fig. 3 shows a stable reduction in numbers of rural people in absolute poverty. However, absolute poverty and low income are still important problems (NBSC, 2001-2007). For instance, at the end of 2006, the total Chinese population reached 1,314.48 million, of which the rural population constituted $56.1 \%$. The population in absolute poverty in rural areas with annual per capita net income below 693 yuan numbered 21.48 million, and the low-income population in rural areas with annual per capita net income between 694 and 958 yuan numbered 35.50 million. This widespread poverty stands in the way of rural informatization.

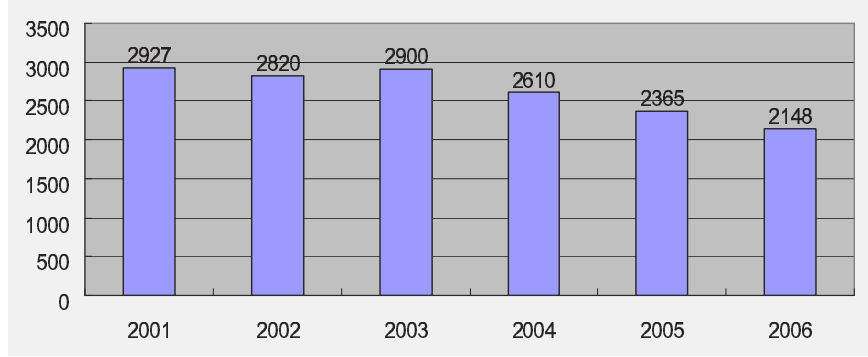

Fig. 3. Number $\left(\times 10^{4}\right)$ of people in absolute poverty in rural areas

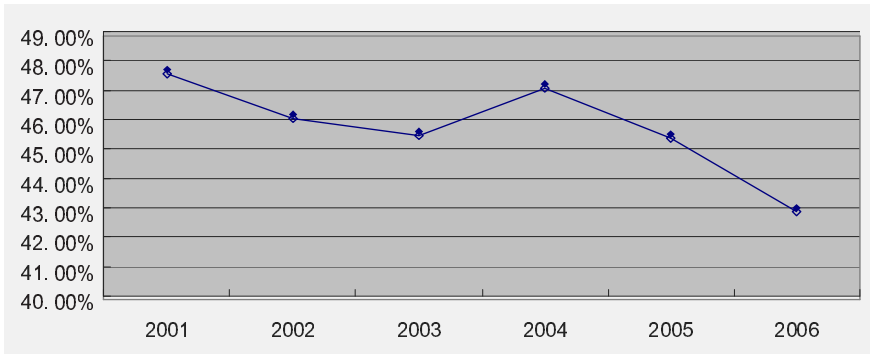

Fig. 4. Engel coefficient for rural households 


\section{RECOMMENDATIONS}

After analyzing the status of developing rural informatization in China, there are some simple recommendations put forward in order to accelerate further rural informatization.

\subsection{Government promotion and infrastructure construction}

In the construction of villages and dissemination of rural informatization, the government's role as leader should be the provision of funds, development of legislation, regulation of inter-departmental relations, and construction of infrastructure and so on. Bridging the digital divide and solving "the last mile" requires the leadership of government (Guo et al., 2006).

\subsection{Optimism and confidence}

Although developing quickly in the past twenty years, the internet is still very young. The internet is becoming increasingly more established and individuals around the world are learning to use the web's many functions. For people on the wrong side of the technology tracks, the government and non-profit organizations should provide residents of rural and remote areas with more training opportunities. It is important for them to relinquish doubts and fears and take part in training programs with confidence and optimism.

\subsection{Training and discussion}

The internet is accessible to everyone, irrespective of age, gender, religion, income, nationality and level of literacy. Training is a key process to assist disadvantaged farmers. After training, farmers should be able to master sufficient expression skills to be able to describe problems clearly and obtain detailed explanations from experts. Without relevant training, farmers are unsure how to put forward a problem, or problems are outlined in terminology that is too general and ambiguous for experts to understand and resolve.

A typical example (Singh, 2003) shows the necessity of training. Before training, experts received this question from a 32-year old resident of a village: "I observed flowers dropping in my castor field, please advise me." The advice of experts to this situation was "We need adequate information to understand the problem." After training, the same question was repeated as follows: "In the 3-month-old castor crop on my 4 acres of land, I have 
observed two kinds of flowers, red and green; only the red ones turned into fruit while the green flowers fell from the plants. Please advise me." To this more detailed question, the advice of experts was: "Green flowers are male flowers. After fertilization, male flowers fall off and the red female flowers turn into fruit. This is natural and there is no need for taking any measure." (Dileep et al., 2006).

\subsection{Solution of localization issues}

China is a large country with a vast territory, comprising 56 ethnic groups with their own language or dialect. Localization is a serious issue in the spreading of agricultural informatization, because local names vary from one location to another even within a province. Experts often use scientific names in their discussions (Guntuku et al., 2006). How can this problem be solved? There are two effective measures. One is to popularize agricultural knowledge in all rural areas, which is a long-term task, and the other is to train local personnel at an information station and broadcast information downloaded from the internet to the rural population in the local language, which will quickly solve some problems to a certain extent.

\subsection{Satisfactory goods and service}

According to American researchers, the consumer will disseminate his/her dissatisfaction at an astonishing speed when he/she is not content with the goods or services provided by enterprises, government or organizations (Chen, 2004). Fig. 5 describes the process of dissemination. For every consumer who expresses his/her discontentment to the providers of the goods or services, there are 26 dissatisfied consumers who remain silent. However, each of the 26 dissatisfied consumers will transmit his/her discontentment to 10 other people, and one-third of each of those 10 will transmit the information to a further 20 people.

In reality, only one consumer is dissatisfied with the good or service but, in fact, many more people become potential consumers affected by negative information. The detailed calculation is as follows:

Level $1 \quad 1+26=27$

Level $226 \times 10=260$

Level $31 / 3 \times 10 \times 26 \times 20=1733$

In level 1, there are 27 dissatisfied consumers; in level 2, there are 260 potential consumers affected; and in level 3, there are 1733 potential consumers affected. 


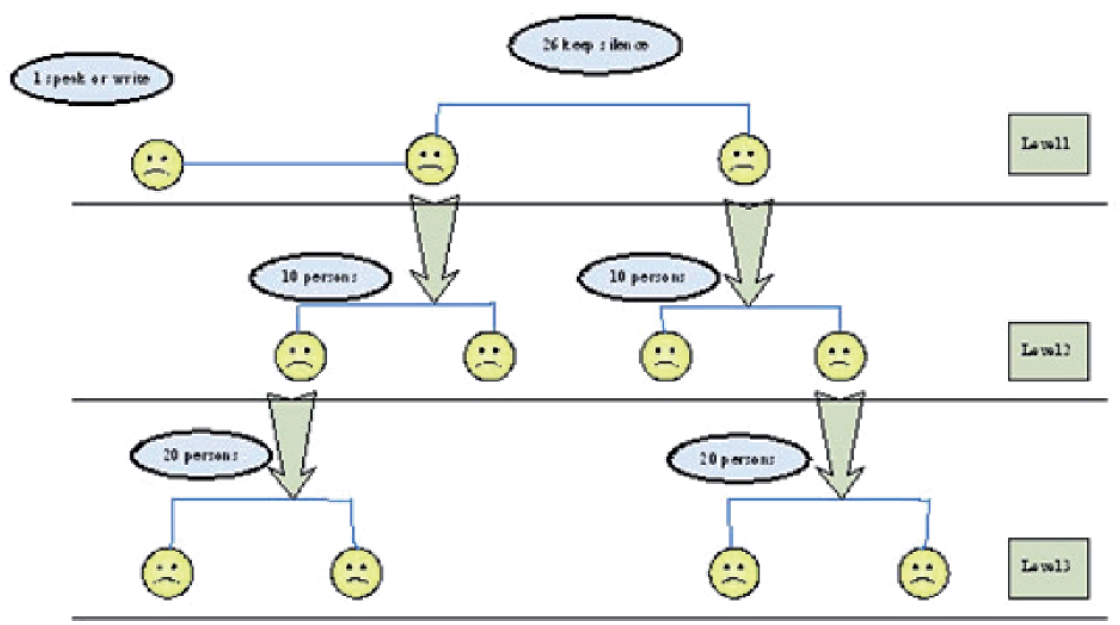

Fig. 5. Dissemination of dissatisfaction

During the process of developing rural informatization, residents in rural and remote areas are sensitive consumers. High quality facilities and highgrade services will attract consumers step by step, and inferior production will hinder the development of rural informatization.

\section{CONCLUSION}

The aim of developing rural informatization is to improve agricultural yields and improve rural conditions. There are many differences between different areas; it is impossible and unnecessary to purchase a computer for every resident of rural and remote areas. Which model and which technology should be adapted? Although a "one-size-fits-all" solution does not exist: different circumstances may dictate different choices, the following measures are important to develop agricultural and rural informatization: strengthening government promotion and constructing infrastructure, increasing the optimism and confidence of farmers, providing training and facilitating discussion and providing satisfactory goods and services to farmers.

\section{ACKNOWLEDGMENTS}

The author wishes to thank Ms. Robyn Chesney and Mr. Wang Qingjie to revise and polish this paper. 


\section{REFERENCES}

Chen Diange, Market Investigation and Forecast, Qinghua University Publication, 2004.

Dileep Kumar Guntuku, Aruna Sai Kuna, Sreenath Dixit, Balaji Venkataraman. Information and Communication Technology (Ict) Mediated Open Distance Learning (Odl) Methods for Agricultural Extension: A Case Study From a Drought Prone Area of Rural South Asia, Computers in Agriculture and Natural Resources, 4th World Congress Conference, Proceedings of the International Conference, 2006, pp. 188-192.

Guo Ruilin, Guan Li, Zhang Jinzhong, The Existing Problems and Developing Counter measures of Agricultural Information in Henan Province, Chinese Agricultural Science Bulletin, Vol. 22, No. 2, 2006: pp. 392-394.

Li Xianglan, Benefit the Experience of developed countries, built an innovation system of agricultural information service suited the concrete situation in our country, Agricultural Network Information, Vol. 2, 2006: pp. 8-12.

NBSC (National Bureau of Statistics of China), China statistical Yearbook 2001, China statistic Press, 2001.

NBSC (National Bureau of Statistics of China), China statistical Yearbook 2002, China statistic Press, 2002.

NBSC (National Bureau of Statistics of China), China statistical Yearbook 2003, China statistic Press, 2003.

NBSC (National Bureau of Statistics of China), China statistical Yearbook 2004, China statistic Press, 2004.

NBSC (National Bureau of Statistics of China), China statistical Yearbook 2005, China statistic Press, 2005.

NBSC (National Bureau of Statistics of China), China statistical Yearbook 2006, China statistic Press, 2006.

NBSC (National Bureau of Statistics of China), China statistical Yearbook 2007, China statistic Press, 2007.

Nirvikar Singh, India's information technology sector: what contribution to broader economic development, OECD Development center, (Working Paper No. 207), 2003.

Tong Peijie, The Gap of Internet is Shrinking, China Computer Users, Vol. 28, 2006: pp. 13.

Wan Honghui, Wang Junhui, Feng Lu, Study on Difficulties Faced in Agricultural Information Service in Yunnan Province and its Development Counter Measures, Journal of Library and Information Sciences in Agriculture, Vol. 18, No. 01, 2006: pp. 39-41.

Wang Yuzhen, Research on Some Problems of Countryside's informatization in Gansu Province, Agricultural Network Information, Vol. 1, 2006: pp. 37-39.

Yao chunhua, Analysis on the Application and development of VSAT in Village Coverage Project, 2007 http://www.cww.net.cn/article/article.asp?id=76607\&bid=2816 